\title{
TITLE:
}

\section{Sources of polyatomic ions of organic liquids}

$\operatorname{AUTHOR}(\mathrm{S}):$

Takaoka, G. H.; Takeuchi, M.; Ryuto, H.

CITATION:

Takaoka, G. H.... [et al]. Sources of polyatomic ions of organic liquids. REVIEW OF SCIENTIFIC INSTRUMENTS 2010, 81(2): $02 B 302$.

\section{ISSUE DATE:}

2010-02

URL:

http://hdl.handle.net/2433/147204

\section{RIGHT:}

Copyright 2010 American Institute of Physics. This article may be downloaded for personal use only. Any other use requires prior permission of the author and the American Institute of Physics. The following article appeared in REVIEW OF SCIENTIFIC INSTRUMENTS81, 02B302 (2010) and may be found at 


\title{
Sources of polyatomic ions of organic liquids ${ }^{a)}$
}

\author{
G. H. Takaoka, ${ }^{\text {b) }}$ M. Takeuchi, and H. Ryuto \\ Photonics and Electronics Science and Engineering Center, Kyoto University, Kyoto 615-8510, Japan
}

(Presented 24 September 2009; received 11 September 2009; accepted 3 October 2009; published online 5 February 2010)

\begin{abstract}
We have developed two types of liquid ion sources, one of which was a polyatomic ion source using liquid organic materials with a high-vapor pressure. Liquid materials such as octane and ethanol could be heated up to a maximum temperature of $100{ }^{\circ} \mathrm{C}$, and the vapors were introduced into an ion source. They were ionized by an electron bombardment method and extracted from the ionizer. The ion current obtained at an extraction voltage of $2 \mathrm{kV}$ was $230 \mu \mathrm{A}$ for octane and several fragment ions such as alkyl ions were produced. On the other hand, another type of polyatomic ion source using alkyl naphthalene mixed with ionic liquid such as imidazolium dicyanamide has been developed. Instead of the electron bombardment method, a high-electric field method was used for the ion-emission from a sharp tip, because the vapor pressure of the liquid materials was relatively low. The threshold voltage was approximately $4.5 \mathrm{kV}$ and the ion current of approximately $250 \mathrm{nA}$ was obtained at an extraction voltage of $9.5 \mathrm{kV}$. (C) 2010 American Institute of Physics.
\end{abstract}

[doi:10.1063/1.3258426]

\section{INTRODUCTION}

The development of ion sources has attracted much interest from fundamental and applicable viewpoints. ${ }^{1,2}$ Various kinds of ions such as positive and negative ions, singly and multiply charged ions, monomer and cluster ions are available and they are applied to various scientific and technological fields. Among these ions, polyatomic ions exhibit unique features, one of which is that it can transfer the energy and the mass as well as the fragment radical toward a solid surface. This feature is effective to enhance surface reaction caused by high-energy-density irradiation effect during impact of polyatomic ions on the solid surface. Another feature is that equivalently low-energy transfer is achieved using polyatomic ion beams. This feature is effective to achieve shallow implantation, which has received more attention in engineering applications. ${ }^{3,4}$ Based on these features, polyatomic ion beams have a high potential in functional surface formation and surface modification. ${ }^{5}$

Polyatomic ion is a particle with a definite size and a determinate structure. With regard to the size, that is defined as the number of component atoms forming a polyatomic ion, the number aimed in this article is from a few atoms to several tens atoms. This range includes the critical number indicating a transient collision process from binary collision of atomic ions to multiple collisions of polyatomic ions. Therefore, it is much interesting to clarify the critical number of atoms from the experimental point of view. Thus, from fundamental and applicable viewpoints, the development of polyatomic ion sources is of significant importance. Furthermore, in liquid materials, various kinds of polyatomic mol-

\footnotetext{
a) Contributed paper, published as part of the Proceedings of the 13th International Conference on Ion Sources, Gatlinburg, Tennessee, September 2009.

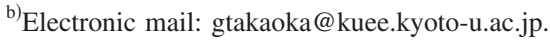

ecules consisting of various kinds of radicals, as well as the critical number of atoms are available. Also, liquid materials can be applied to surface modification of solid materials by ion beams and they can be supplied continuously to an ion source.

In this article, two types of liquid ion sources are described. One is a polyatomic ion source using octane with a high-vapor pressure. Another is a polyatomic ion source using alkyl naphthalene with a relatively low-vapor pressure. Furthermore, mass separation spectra for octane ion beams and threshold voltage for alkyl naphthalene ion beams are investigated, and beam characteristics are discussed.

\section{DESIGN OF ION SOURCES}

\section{A. Polyatomic ion source for a high-vapor pressure of materials}

Figure 1 shows a schematic illustration of the polyatomic ion source for a high-vapor pressure of materials. The ion source consists of mainly a capillary type of nozzle and an ionizer. Liquid materials such as octane and ethanol can be heated up to a maximum temperature of $100{ }^{\circ} \mathrm{C}$ outside a vacuum chamber, and the vapors of liquid materials are introduced into the source through a stainless steel tube with a diameter of $3 \mathrm{~mm}$. In the ion source, the vapors are ejected through the nozzle into the ionizer. In the ionizer consisting of a tungsten filament and a mesh-type of anode, the vapors are ionized by electron bombardment. The diameter of the tungsten filament was $0.3 \mathrm{~mm}$, and the diameter of the anode was $25 \mathrm{~mm}$. The ionization voltage was applied between the filament holder and the anode. The electron voltage for ionization $\left(\mathrm{V}_{\mathrm{e}}\right)$ was adjusted between 0 and $300 \mathrm{~V}$, and the electron current for ionization $\left(\mathrm{I}_{\mathrm{e}}\right)$ was adjusted between 0 and $200 \mathrm{~mA}$. The polyatomic ions including fragment ions 


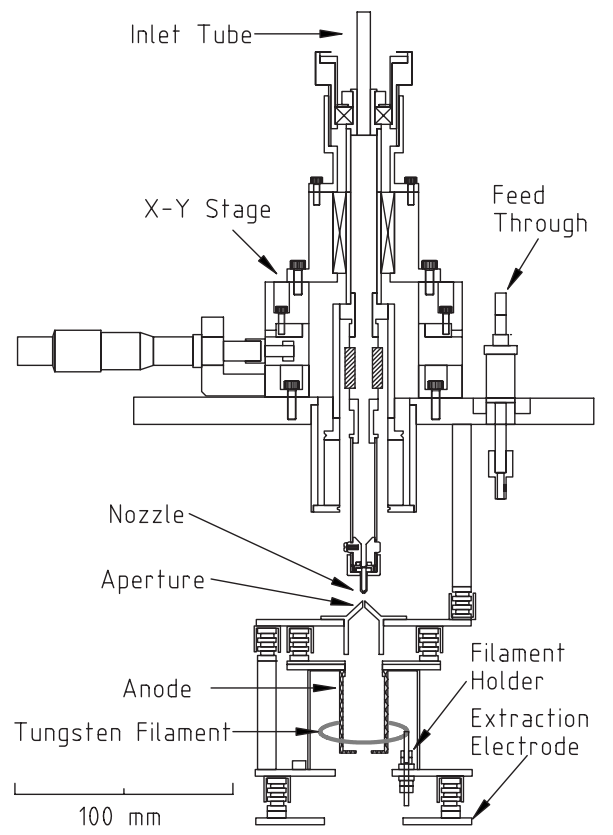

FIG. 1. Schematic illustration of polyatomic ion source for a high-vapor pressure of material.

are extracted by applying a voltage between the filament holder and the extraction electrode. The extraction voltage $\left(\mathrm{V}_{\text {ext }}\right)$ was adjusted between 0 and $5 \mathrm{kV}$.

In the experimental system used, the extracted ions were focused by an einzel lens and deflected by applying an voltage to the deflection electrode. The deflected ions entered a mass separator such as $\mathrm{E} \times \mathrm{B}$ filter (Wien filter), in which ion beam axis, electric field (E) and magnetic field (B) are all mutually perpendicular. The mass-separated ion beams by adjusting the electric field in the $\mathrm{E} \times \mathrm{B}$ filter were accelerated toward a Faraday cup. The acceleration voltage $\left(\mathrm{V}_{\mathrm{a}}\right)$ was adjusted between 0 and $10 \mathrm{kV}$. The fluence of ions was determined based on the collected ion current by the Faraday cup. When the desired ion fluence was attained, the shutter was closed to terminate ion current. The background pressure around the Faraday cup was $8 \times 10^{-7}$ Torr, which was attained using a turbo-molecular pump.

\section{B. Liquid ion source for a relatively low-vapor pressure of materials}

Alkyl naphthalene is well known as vacuum pump oil, and the vapor pressure is relatively low such as 5.5 $\times 10^{-7}$ Torr at room temperature. The wettability to carbon surface is excellent, and the contact angle was approximately $4^{\circ}$. On the other hand, ionic liquid, which is a molten salt with a relatively low-vapor pressure, is optical transparent and electrical conductive. The wettability to carbon surface is not good, and the contact angle was larger than $40^{\circ}$. Ionic liquid used was 1-ethyl-3-methylimidazolium dicyanamide $\left(\mathrm{C}_{8} \mathrm{H}_{11} \mathrm{~N}_{5}\right)$. As shown in Fig. 2, the polyatomic ion source for liquid materials such as alkyl naphthalene and ionic liquid has been developed. A high-electric field method is employed for the ion-emission from a sharp tip made of carbon rod. The diameter of the rod was $3 \mathrm{~mm}$. As a tip designed, for instance, an arrow type of needle is employed as shown

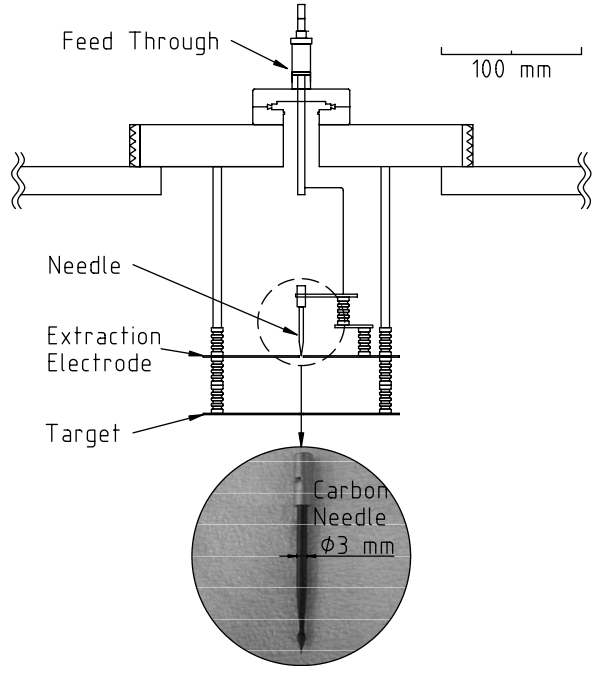

FIG. 2. Schematic illustration of liquid ion source for a relatively low-vapor pressure of material.

in the figure. The ions are extracted from the tip by applying the voltage between the tip and the extraction electrode. A high-electric field is formed by using the sharp tip with a radius of a few tens of micrometers. The extraction voltage was adjusted between 0 and $10 \mathrm{kV}$. The aperture made on the extraction electrode was $3 \mathrm{~mm}$ in the diameter, and the distance between the tip and the extraction electrode was $1 \mathrm{~mm}$. The ions extracted are moved toward a target, on which they are collected as an ion current. The background pressure around the target was $1 \times 10^{-6}$ Torr, which was attained using a diffusion pump.

\section{RESULTS AND DISCUSSION}

\section{A. Mass separation characteristics}

The mass spectra of octane ion beams were investigated using an $\mathrm{E} \times \mathrm{B}$ filter. Several fragment ion beams were obtained, whereas the intensity of $\mathrm{C}_{8} \mathrm{H}_{18}$ ion beams was very weak. Among the fragment ions, the highest concentration was $\mathrm{C}_{3} \mathrm{H}_{7}$ ion with a mass number of 43 and the second highest concentration was $\mathrm{C}_{2} \mathrm{H}_{5}$ ion with a mass number of 29. Figure 3 shows the dependence of the extracted ion current as well as the $\mathrm{C}_{6} \mathrm{H}_{13}, \mathrm{C}_{3} \mathrm{H}_{7}$, and $\mathrm{C}_{2} \mathrm{H}_{5}$ fragment ion current on the electron current for ionization. The electron voltage for ionization $\left(\mathrm{V}_{\mathrm{e}}\right)$ was $250 \mathrm{~V}$. The extraction voltage

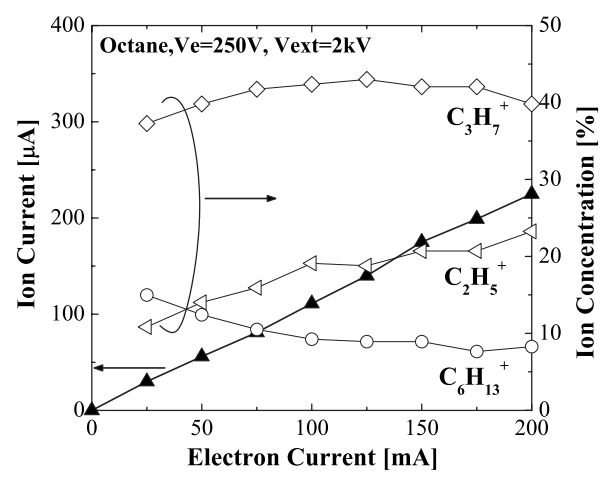

FIG. 3. Dependence of the extracted ion current as well as the $\mathrm{C}_{6} \mathrm{H}_{13}, \mathrm{C}_{3} \mathrm{H}_{7}$, and $\mathrm{C}_{2} \mathrm{H}_{5}$ fragment ion current on the electron current for ionization. 


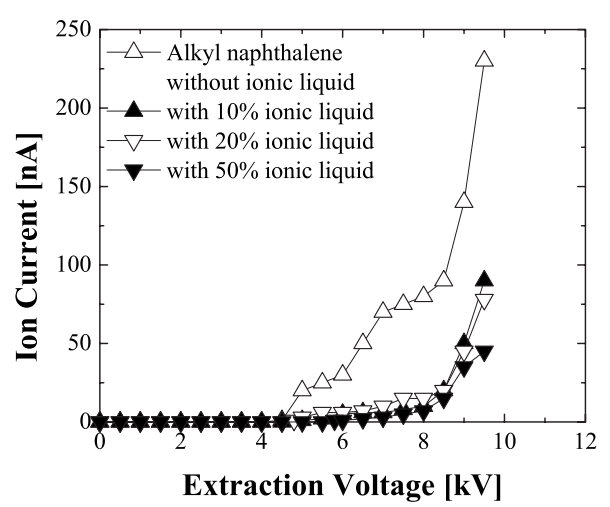

FIG. 4. Dependence of the ion current of alkyl naphthalene with and without ionic liquid on the extraction voltage.

$\left(\mathrm{V}_{\text {ext }}\right)$ was kept at $2 \mathrm{kV}$. As shown in the figure, the extracted ion current increases with increase in the electron current for ionization, and the extracted current of $230 \mu \mathrm{A}$ is obtained at an electron current of $200 \mathrm{~mA}$. With regard to the fragment ions, the concentration of $\mathrm{C}_{6} \mathrm{H}_{13}$ ion decreases with increase in the electron current, whereas $\mathrm{C}_{2} \mathrm{H}_{5}$ ion concentration increases with increase in the electron current. This is ascribed to the enhancement of the dissociation of $\mathrm{C}_{6} \mathrm{H}_{13}$ ions into smaller mass fragment ions such as $\mathrm{C}_{2} \mathrm{H}_{5}$ ions by the electron bombardment at higher electron currents. In general, $\mathrm{C}_{8} \mathrm{H}_{18}$ molecule is dissociated by electron bombardment, and the highest concentration of fragment ions is considered to be $\mathrm{C}_{3} \mathrm{H}_{7}$ ion. The amount of the $\mathrm{C}_{3} \mathrm{H}_{7}$ ion increase with increase of the electron current, and it decreases slightly at an electron current of $200 \mathrm{~mA}$. Because the extracted ion current increases with increase of the electron current, the $\mathrm{C}_{3} \mathrm{H}_{7}$ ions might be expected to increase. However, the decrease of $\mathrm{C}_{3} \mathrm{H}_{7}$ ion concentration at higher electron currents occurs as shown in the figure. This is due to its dissociation to another fragment ion with smaller mass such as $\mathrm{C}_{2} \mathrm{H}_{5}$ ion or $\mathrm{CH}_{3}$ ion, which exhibited gradual increase of ion concentration in the mass spectra measurement.

\section{B. Threshold voltage for ion emission}

For the high-electric field emission of ions, the emission area is extremely small like a tip point. Therefore, highdensity ion current is available, even if the extraction ion current is small. Figure 4 shows the dependence of the ion current of alkyl naphthalene with and without ionic liquid on the extraction voltage. For the alkyl naphthalene without ionic liquid, the ions start to be emitted at an extraction voltage of approximately $4.5 \mathrm{kV}$. The ion current increases with increase of the extraction voltage, and it is approximately $250 \mathrm{nA}$ at an extraction voltage of $9.5 \mathrm{kV}$. When some volume percent of ionic liquid is mixed with the alkyl naphthalene, the ion current extracted decreases, and the threshold voltage is shifted to a higher voltage than $5 \mathrm{kV}$. From the theoretical viewpoint, the threshold voltage $\mathrm{V}_{\text {th }}$ is given by ${ }^{6}$

$$
\mathrm{V}_{\mathrm{th}}=\sqrt{\frac{\gamma r_{t}}{\varepsilon_{0}}} \ln \frac{4 d}{r_{t}},
$$

where $\varepsilon_{0}$ is the electric constant, $\gamma$ is the surface energy, $r_{t}$ is the radius of the tip, and $d$ is the distance between the tip and the extraction electrode. When the surface energy is large, the threshold voltage becomes large. This suggests that the surface energy of the mixed liquid becomes large compared with the alkyl naphthalene. In order to evaluate the surface energy, the contact angle was measured. It showed that the contact angle to carbon surface was approximately $4^{\circ}$ for alkyl naphthalene and $43^{\circ}$ for ionic liquid, respectively. Therefore, the surface energy of the ionic liquid is larger than that of the alkyl naphthalene, which results in increase of the threshold voltage for the mixed liquid. It should be noted that the ion current of 1-ethyl-3-methylimidazolium dicyanamide $\left(\mathrm{C}_{8} \mathrm{H}_{11} \mathrm{~N}_{5}\right)$ was not obtained. This is considered to be due to the bad wettability to carbon surface, and Taylor cone could not be formed on the tip. In addition, the mass separation was not conducted for the mixed liquid materials, and it was not clear in this article whether ionic liquid ion was included or not.

In summary, two types of liquid ion sources were developed, one of which was a polyatomic ion source using liquid organic materials with a high-vapor pressure. In the ion source, the vapors of octane were ionized by electron bombardment, and the ion current of $230 \mu \mathrm{A}$ was obtained at an extraction voltage of $2 \mathrm{kV}$. The mass spectra showed that the fragmentation of octane occurred by electron bombardment, and $\mathrm{C}_{3} \mathrm{H}_{7}$ ion was highest in the ion concentration. In order to reduce the fragmentation of octane, it might be effective to reduce the electron voltage for ionization such as $\mathrm{V}_{\mathrm{e}}<50 \mathrm{~V}$.

On the other hand, another type of polyatomic ion source using alkyl naphthalene mixed with ionic liquid such as imidazolium dicyanamide was developed. In the ion source, a high-electric filed method was used, and the threshold voltage was approximately $4.5 \mathrm{kV}$. The ion current of approximately $250 \mathrm{nA}$ was obtained at an extraction voltage of 9.5 $\mathrm{kV}$. In order to produce ionic liquid ion beams, it is of much importance to select proper material for a tip, which represents a good wettability.

${ }^{1}$ J. Ishikawa, Rev. Sci. Instrum. 79, 02 C506 (2008).

${ }^{2}$ D. G. Armour, AIP Conf. Proc. 1066, 3 (2008).

${ }^{3}$ K. Goto, J. Matsuo, T. Sugii, H. Minakata, I. Yamada, and T. Hisatsugu, Tech. Dig. - Int. Electron Devices Meet. 1996, 17.1.1.

${ }^{4}$ Y. Kawasaki, T. Kuroi, T. Yamashita, K. Horita, T. Hayashi, M. Ishibashi, M. Togawa, Y. Ohno, M. Yoneda, T. Horsky, D. Jacobson, and W. Krull, Nucl. Instrum. Methods Phys. Res. B 237, 25 (2005).

${ }^{5}$ G. H. Takaoka, Y. Nishida, T. Yamamoto, and M. Kawashita, Nucl. Instrum. Methods Phys. Res. B 237, 240 (2005).

${ }^{6}$ R. Gomer, Appl. Phys. (Berlin) 19, 365 (1979). 